\title{
$\begin{array}{ll}\text { Research Square } & \text { Preprints are preliminary reports that have not undergone peer review. } \\ \text { They should not be considered conclusive, used to inform clinical practice, }\end{array}$ or referenced by the media as validated information. \\ Effects of Oyster Shell Powder on Leaching Characteristics of Nutrients in Latosol
}

\section{Xiaofei Yang}

Guangdong Ocean University

\section{Yongxiang Huang}

Guangdong Ocean University

\section{Kexing Liu}

South China Agricultural University

Chao Zheng ( $\nabla$ zhengchao@gdou.edu.cn )

Guangdong Ocean University

\section{Research Article}

Keywords: oyster shell powder, latosol, nutrient, leaching, water content, leaching loss, soil pH, water loss

Posted Date: January 25th, 2022

DOI: https://doi.org/10.21203/rs.3.rs-1177796/v1

License: (9) This work is licensed under a Creative Commons Attribution 4.0 International License. Read Full License 


\section{Effects of oyster shell powder on leaching characteristics of nutrients in latosol}

\section{Xiaofei Yang ${ }^{1}$, Yongxiang Huang ${ }^{2}$, Kexing Liu ${ }^{3}$, Chao Zheng ${ }^{1 *}$}

${ }^{1}$ Faculty of Chemistry and Environmental Science, Guangdong Ocean University, Zhanjiang 524088, China

${ }^{2}$ College of Coastal Agricultural Sciences, Guangdong Ocean University, Zhanjiang 524088, China

${ }^{3}$ College of Natural Resources and Environment, South China Agricultural University, Guangzhou 510642,

\section{China}

\section{*Corresponding author: Chao Zheng}

Faculty of Chemistry and Environmental Science, Guangdong Ocean University

Zhanjiang 524088, China

Phone: 13670973108

Fax: 0759-2383279

Email: zhengchao@gdou.edu.cn

\footnotetext{
Abstract

In this study, we analyzed the effect of oyster shell powder of different proportions on the nutrient leaching characteristics of latosol, using an indoor soil column simulation test. Based on the optimized fertilizer application amount, we tested five different amounts of oyster shell powder in the test [0\% (control, CK), $0.1 \%$ (T1), $0.2 \%$ (T2), $0.4 \%$ (T3), and $0.8 \%$ (T4)] for analyzing the intermittent and dynamic leaching characteristics of nutrients in the soil samples. The results indicated that the loss of nutrients in urea, superphosphate, and potassium chloride (due to leaching) increased linearly with the amount of fertilizer. By adding oyster shell powder, the leaching loss reduced by $23.90-57.25 \%$ for ammonium nitrogen, $6.31-10.07 \%$ for phosphorus, and 17.08-26.58\% for potassium. However, the leaching loss for nitrate nitrogen increased by 2.5-5.8 times. In addition, the application of oyster shell powder to latosol provided acid adjustment and water retention enhancement, which increased the $\mathrm{pH}$ value of the soil by 3.77 (from $\mathrm{pH} 4.15$ to 7.92 ) and reduced water loss by $2.52 \%$. Thus, the application of oyster shell powder can reduce the acidity of the surface soil and retain water and fertilizer to a certain extent; however, it may increase the potential risk of nitrate nitrogen pollution in groundwater.
} 
32 Keywords: oyster shell powder; latosol; nutrient; leaching; water content; leaching loss; soil pH; water loss 


\section{Introduction}

The Guangdong Province of China is in a typical subtropical zone, where abundant rainfall causes nutrient leaching in soil, along with its acidification. Studies have shown that acidic soil accounts for approximately 30 $\%$ of the total land area globally (Guo et al. 2010), and soil acidification has become a growing concern as well. Latosol is an acidic, zonal soil, with thick layers. It is sticky and heavy and has poor fertility. Notably, acidic fertilizers were applied excessively in Guangdong Province; these fertilizers cannot be fully absorbed by the crops, thus, aggravating the soil acidification problem. Consequently, the soil in this region is unsuitable for the production of local tropical cash crops and causes environmental pollution due to leaching (Jiang et al. 2019).

Leaching is a significant mechanism of fertilizer loss, because the fertilizer is not easily adsorbed by the solid phase of the soil, and thus, often seeps down into the earth with water (Islam et al. 2016; Elbl et al. 2020; Wang et al. 2021). Daniel et al. (2021) deduced that the loss of nitrate nitrogen due to soil leaching can be as high as $36 \%$ of the amount of nitrogen applied, resulting in groundwater pollution and eutrophication of water bodies. Notably, phosphorus in soil is rarely leached due to its adsorption by soil colloids, but long-term use of excessive fertilizer may ultimately cause phosphorus leaching. Tunney et al. (1997) and Sharpley et al. (1984) observed a linear increase in phosphorus leaching when phosphate fertilizer was applied such that the available phosphorus content in the soil exceeded $60 \mathrm{mg} / \mathrm{kg}$. In addition, recent studies have revealed that potassium in soil is prone to leaching, due to the intensification of soil acidification (Krause 1965), resulting in the depletion of potassium in latosol, which makes the soil non-conducive to the growth of crops. Therefore, the leaching of nutrients added in the soil through fertilizers is an important factor that restricts the local agricultural production, which in turn, causes environmental problems that must be solved urgently.

Oyster shell powder is a widely used soil conditioner discovered in recent years and can also be used as a fertilizer to provide nutrients directly for the growth and development of crops (Eo et al. 2018; Lee et al. 2020; Hong et al. 2021). The application of alkaline oyster shell powder to the soil, along with long-term application of chemical fertilizers, can alleviate soil compaction and acidification, thus, playing a positive role in increasing crop production. Park and Polprasert (2008) and Jay et al. (2019) indicated that the naturally porous surfaces of oyster shells can increase the adsorption of nutrients and are ideal for substance attachment. Notably, oysters are abundant in the coastal areas of China, and the use of oyster shells (that are otherwise wasted) can not only reduce environmental pollution, but also improve the fertility of soil to a certain extent. However, there are only a few studies on the improvement of latosol using oyster shell powder. The relevant studies regarding oyster 
shell powder mainly focus on adjusting the $\mathrm{pH}$ value (Yinglan et al. 2016), whereas nutrient leaching has been rarely mentioned. As a result, the rational application of oyster shell powder requires further study.

In this study, to optimize the application amounts of nitrogen $(\mathrm{N})$, phosphorus $(\mathrm{P})$, and potassium $(\mathrm{K})$ fertilizers, different amounts of oyster shell powder were added to the same amount of fertilizers to create different mixtures. These mixtures were applied to the latosol samples in an indoor soil column leaching test. By analyzing the $\mathrm{pH}$ value and nutrient contents of the leaching solution, we were able to study the effects of oyster shell powder on the acidity adjustment and fertilizer retention capacity of latosol, providing a theoretical foundation for the improvement of the latosol and promoting the reuse of oyster shells, which are otherwise, considered to be marine waste.

\section{Materials and Methods}

\section{Test materials}

This study was carried out at the Institute of Agricultural Biotechnology, Guangdong Ocean University $\left(110^{\circ} 30^{\prime} 07^{\prime \prime} \mathrm{E}, 21^{\circ} 14^{\prime} 85^{\prime \prime} \mathrm{N}\right)$ between April 2021 and June 2021. The institute is located in an important agricultural base of tropical cash crops. The latosol sample soil was taken from 0-20 cm from the surface; notably, the latosol developed from basalt, which rendered it a sticky texture. Latosol samples were taken from a banana planting base of Guangdong Ocean University $\left(110^{\circ} 29^{\prime} 09^{\prime \prime} \mathrm{E}, 21^{\circ} 15^{\prime} 31^{\prime \prime} \mathrm{N}\right)$, which has a tropical and subtropical monsoon climate. The annual average temperature is $23.0^{\circ} \mathrm{C}$, the annual average precipitation is $>1417 \mathrm{~mm}$, and the rainy season is from April to September. Tropical storms and typhoons are frequent in summer and autumn, and soil erosion is serious. We used pipe-type soil drills to extract samples at five points according to the S-shaped line, and $10 \mathrm{~kg}$ of latosol was collected from each point. The soil was clay soil, with clay content of $64.24 \%$ and a water holding capacity of $23.80 \%$. After extraction, the soil samples were immediately transferred to the laboratory for pretreatment. The collected soil was mixed evenly, dried under natural conditions, and stored at room temperature for later use after passing through a $1 \mathrm{~mm}$ sieve. The basic physiochemical properties of the soil samples are shown in Table 1; we observed that latosol is particularly deficient in phosphorus and potassium, and the overall fertility of the soil is moderately low.

The NPK fertilizers used in the test were urea (46\% N content), superphosphate (16\% $\mathrm{P}_{2} \mathrm{O}_{5}$ content), and potassium chloride (60\% $\mathrm{K}_{2} \mathrm{O}$ content), all purchased from Yangmei Chemical Co., Ltd., located in Suichuan County, Jiangxi Province, China. Waste oyster shells were collected from the Xiashan aquatic product wholesale market in Zhanjiang, Guangdong Province, China. The collected shells were first soaked in tap water 
for $4 \mathrm{~h}$ and then, rinsed to remove sand and surface debris. The rinsed oyster shells were then, placed in $0.5 \%$ hydrochloric acid and continuously stirred for $1 \mathrm{~h}$ before being removed. A large amount of tap water was used to wash the oyster shells until the $\mathrm{pH}$ value of water reached a neutral value. Distilled water was used to clean the oyster shells twice. The oyster shells were finally placed in an oven to dry and then, fully crushed into oyster shell powder having an average particle size of $0.15 \mathrm{~mm}\left(96.8 \% \mathrm{CaCO}_{3}\right.$ content, $\left.\mathrm{pH} 9.47\right)$, which was collected in a dryer for later use. Notably, all the chemicals used were of analytical grade.

\section{Leaching simulation device}

The leaching simulation device used in our study was made of 60 PVC pipes, corresponding custom-made fixed support brackets, and a solution collecting device. The PVC soil column had an outer diameter of $6.3 \mathrm{~cm}$, inner diameter of $5.9 \mathrm{~cm}$, and height of $34.5 \mathrm{~cm}$. In addition, the bottom of the PVC soil column was wrapped with a 200-mesh nylon net, which was tightened using specified plastic brackets, to prevent the internal contents from leaking. Inside the soil column, the bottom and the uppermost layers were laid with $150 \mathrm{~g}$ of $1-2 \mathrm{~mm}$ quartz sand, which were washed and dried using deionized water to form a sand layer that was $\sim 3 \mathrm{~cm}$ thick, preventing the disturbance of the soil layers and providing filtration. Notably, at the same time, the soil at the edges of the PVC pipes was compacted to ensure that the water flow during leaching did not penetrate and flow along the pipe walls, thus reducing edge effects. Finally, a soil column of approximately $20 \mathrm{~cm}$ was constructed, and the installed PVC pipes were numbered and fixed on the supporting frame for use. The structure of the setup used in our study is shown in Fig. 1.

\section{Experimental design}

In this study, we conducted two column tests using latosol samples; we used urea as the source of nitrogen, superphosphate as the source of phosphorus, and potassium chloride as the source of potassium to study the nutrient leaching characteristics of different amounts of fertilizers in latosol. The experiment was conducted in triplicate, and 60 leaching columns were established [1 soil $\times(5$ urea dosage levels +5 calcium superphosphate dosage levels +5 potassium chloride dosage levels +5 oyster shell powder dosage levels) $\times 3$ replicates]. The first culture experiment included three simlutaneous but independent small experiments: $500 \mathrm{~g}$ of latosol sample was mixed with urea at $0,100,200,400$, and $800 \mathrm{mg} / \mathrm{kg}(\mathrm{w} / \mathrm{w})$, and the urea-soil mixture was loaded into 15 leaching columns. Next, $500 \mathrm{~g}$ of lactosol sample was mixed with calcium superphosphate at 0, 50, 100, 200, and $400 \mathrm{mg} / \mathrm{kg}$ (w/w), and the calcium superphosphate-soil mixture was loaded into 15 leaching columns. In 
addition, $500 \mathrm{~g}$ of latosol sample was mixed with potassium chloride at $0,100,200,400$, and $800 \mathrm{mg} / \mathrm{kg}(\mathrm{w} / \mathrm{w})$, and the potassium chloride-soil mixture was loaded into 15 leaching columns. The height of the mixture was approximately $20 \mathrm{~cm}$, and static water was present $3 \mathrm{~cm}$ from the top. In the second culture experiment, 0.4348 $\mathrm{g}$ urea, $0.6250 \mathrm{~g}$ calcium superphosphate, and $0.3846 \mathrm{~g}$ potassium chloride were added to each $500 \mathrm{~g}$ latosol sample and mixed with oyster shell powder at $0,0.1,0.2,0.4$, and $0.8 \%(\mathrm{w} / \mathrm{w})$, and the oyster shell powder-soil mixture was loaded into 15 leaching columns. Before pouring into the PVC pipe, the mixture was stirred with a glass rod for $5 \mathrm{~min}$ to ensure complete mixing. Distilled water $(200 \mathrm{~mL})$ was added to the soil column to saturate the soil with water and allowed to stand for $24 \mathrm{~h}$. Subsequently, in the first culture experiment the soil column was leachedwith $200 \mathrm{~mL}$ distilled water every $7 \mathrm{~d}$ to complete the $29 \mathrm{~d}$ nutrient leaching test and in the second culture experiment the soil column was leached with $200 \mathrm{~mL}$ distilled water every $5 \mathrm{~d}$ for $21 \mathrm{~d}$. The above is only the proportion of fertilizer and oyster shell powder added to latosol, and the actual dosage is shown in Table 2.

\section{Analysis items and methods}

Multiple tests were carried out to determine the basic physiochemical properties of the latosol (Guo 2009), including measuring the soil $\mathrm{pH}$ value using a $\mathrm{pH}$ meter, with a water-soil ratio of 2.5:1, and determining the soil bulk density using the ring knife method, organic matter content by the volumetric method (using potassium dichromate), amount of alkali-hydrolyzable nitrogen through alkaline hydrolysis, nitrate nitrogen content using the colorimetric method (using phenoldisulphonic acid), ammonium nitrogen content through leaching (using 2 $\mathrm{mol} / \mathrm{L} \mathrm{KCl}$ and an ultra violet-visible spectrophotometer), total phosphorus using $\mathrm{HClO}_{4}-\mathrm{H}_{2} \mathrm{SO}_{4}$ available phosphorus using $0.5 \mathrm{~mol} / \mathrm{L} \mathrm{NaHCO}$, total potassium using $\mathrm{NaOH}$ and flame emission spectrophotometry, and available potassium using $\mathrm{NH}_{4} \mathrm{OAc}$ and leaching and flame emission spectrophotometry.

During the leaching test, the necessary volume of the leaching solution was measured using a graduated cylinder, which was then, mixed fully and measured using a $\mathrm{pH}$ meter to determine its $\mathrm{pH}$ value. An ultraviolet-visible spectrophotometer was used to determine the nitrate nitrogen content. Additionally, Nessler's reagent spectrophotometry method was used to determine the water quality ammonia nitrogen content and oxidation of potassium sulfate; colorimetry with molybdenum blue were used to determine the total phosphorus. Furthermore, flame emission spectrophotometry was used to determine the total potassium in the leaching solution. In addition, the leached amounts of nitrate nitrogen, ammonium nitrogen, total phosphorus, and total 
potassium were measured every 5 or 7 days. The cumulative leached amounts were calculated by adding the leached amounts measured each time.

In the entire test process, the $\mathrm{pH}$ value of the sample was determined using a PHS-3B $\mathrm{pH}$ meter (Instrument and Electrical Science Instrument Co., Ltd., Shanghai, China). The nitrogen in the sample was measured using a $722 \mathrm{G}$ visible spectrophotometer (Shanghai Instrument \& Electrical Analysis Instrument Co., Ltd., Shanghai, China). The phosphorus in the sample was measured using a UV-3100PC UV spectrophotometer (Shanghai Meipuda Instrument Co., Ltd., Shanghai, China). The potassium content was measured using a 6400A flame photometer (Shanghai Precision Scientific Instrument Co., Ltd., Shanghai China).

The cumulative leached amount reflects the degree of nutrient loss during the leaching process of latosol. The larger the value, the more nutrients are lost. Therefore, it is an important indicator for evaluating the degree of nutrient leaching loss. The nutrients used in the tests were nitrate nitrogen, ammonium nitrogen, total phosphorus, and total potassium. The cumulative leaching amount was calculated using the following equation:

$$
\mathrm{L}_{\mathrm{i}}=\sum_{i=1}^{5} \mathrm{C}_{\mathrm{ij}} \times \mathrm{V}_{\mathrm{ij}}
$$

where $L_{i}$ is the cumulative leaching amount for a certain nutrient under treatment $\mathrm{i}(\mathrm{g}) ; C_{i j}$ is the mass concentration of a certain nutrient in the leaching solution under treatment i during the $\mathrm{j}$-th leaching test $(\mathrm{mg} / \mathrm{L})$; and $V_{i j}$ is the volume of the leaching solution under treatment $\mathrm{i}$ during the $\mathrm{j}$-th leaching test $(\mathrm{mL})$.

The leaching loss rate is a measure of the degree of nutrient loss caused by leaching in latosol, and thus, it is an important indicator that affects the utilization of fertilizers. The fertilizers used in our tests were urea, superphosphate, and potassium chloride. The leaching loss rates of the samples were calculated using the following equation:

$$
\mathrm{R}_{\mathrm{i}}=\frac{\mathrm{L}_{\mathrm{i}}-\mathrm{L}_{\mathrm{CK}}}{\mathrm{m}} \times 100 \%
$$

where $R_{i}$ is the leaching loss rate of a certain nutrient under treatment i (\%); $L_{i}$ is the cumulative leaching amount for a certain nutrient under treatment $\mathrm{i}(\mathrm{g}) ; L_{C K}$ is the cumulative leaching amount for a certain nutrient with zero treatment $(\mathrm{g})$; and $\mathrm{m}$ is the amount of fertilizer applied.

The water retention rate can effectively evaluate the effect of the addition of oyster shell powder on the water loss of the latosol, which is an important indicator for verifying the water retention capacity of oyster shell powder in soils. The water retention rates of the samples were calculated using the following equation:

$$
\mathrm{P}_{\mathrm{i}}=\frac{\mathrm{W}_{\mathrm{CK}}-\mathrm{W}_{\mathrm{i}}}{\mathrm{W}_{\mathrm{CK}}} \times 100 \%
$$


where $P_{i}$ is the water retention rate under treatment $\mathrm{i}(\%) ; W_{C K}$ is the total volume of the elution liquid with zero treatment $(\mathrm{mL})$; and $W_{i}$ is the total volume of the elution liquid under treatment $\mathrm{i}(\mathrm{mL})$.

\section{Data processing}

The test data were processed using Microsoft Excel 2010, and the graphs were drawn using Origin 2021. In addition, the least significant difference (LSD) method available in the SPSS 21.0 package was used to analyze the significance level of the differences between the treatments having $\alpha$ values $<0.05$.

\section{Results and Analysis}

\section{Effects of different fertilizer treatments on nutrient leaching characteristics of latosol}

\section{Leaching characteristics of urea in latosol}

As shown in Table 3, the content of nitrate nitrogen in each treatment was significantly higher than that of ammonium nitrogen, indicating that the nitrogen in the soil mainly leached in the form of nitrate nitrogen; the cumulative leaching amount of nitrate nitrogen accounted for $83.68-93.38 \%$ of the total cumulative amount of both nitrate nitrogen and ammonium nitrogen. In general, ammonium nitrogen is easily adsorbed by the soil, and urea continuously decomposes to give ammonium nitrogen in the soil, which causes leaching loss after saturation through adsorption. Except for treatment U0, wherein the ammonium nitrogen concentration continued to decrease, the ammonium nitrogen concentration curves were basically consistent across all treatments, portraying an increasing trend over time. On the $29^{\text {th }}$ day, in addition to the U0 treatment, the ammonium nitrogen concentration peaked in the leaching solution in the cases where urea was added, indicating an increase of $0.17,0.13,0.38$, and $0.50 \mathrm{mg} / \mathrm{L}$ in treatments $\mathrm{U} 1, \mathrm{U} 2, \mathrm{U} 3$, and $\mathrm{U} 4$, respectively. In particular, the cumulative leaching amount of ammonium nitrogen was in the order of $\mathrm{U} 4>\mathrm{U} 3>\mathrm{U} 2>\mathrm{U} 1>\mathrm{U} 0$, with the leaching amount in treatment $\mathrm{U} 4$ being thrice the value in treatment $\mathrm{U} 0$. This indicated that the leaching amount of ammonium nitrogen increased linearly with the amount of nitrogen applied. In addition, when $100 \mathrm{mg} / \mathrm{kg}$ of urea was applied to the latosol, the loss rate of nitrate nitrogen increased by $20.57 \%$ (compared with that of N4), and the loss rate of ammonium nitrogen increased by $132.97 \%$ (compared with that of U4). This indicated that an insufficient amount of urea is more likely to cause leaching losses of nitrate nitrogen and ammonium nitrogen in soil, which is closely related to the conversion rate of external nitrogen sources in soil.

\section{Leaching characteristics of superphosphate and potassium chloride in latosol}


210 As shown in Table 4, as the time and number of leaching tests increased, except for the cases with P0 and P1

211 treatments, the phosphorus concentration in the leaching solution showed a decreasing trend. The rate of

212 decrease was the highest during the first $8 \mathrm{~d}$, and it tended to stabilize after the $8^{\text {th }}$ day. However, for the

213 treatment where superphosphate was added, the cumulative leaching amount was $1.8-8.2$ times that of the P0

214 treatment. For latosol, which is particularly deficient in phosphorus, excessive application of superphosphate can easily lead to phosphorus loss and cause eutrophication in a nearby water body, which is not conducive to the absorption and utilization of phosphorus by crops. Moreover, with the addition of potassium chloride, the treatments had cumulative leaching amounts that were 1.2-9.3 times that of treatment K0, indicating that the cumulative leaching amount of potassium in the soil increased as the fertilizer application amount increased, thus, indicating a relatively ideal linear relationship $\left(\mathrm{R}^{2}=0.9951\right)$.

\section{Effect of oyster shell powder on leaching characteristics of nutrients in latosol}

Effect of oyster shell powder on $\mathrm{pH}$ value of leaching solution

As shown in Fig. 2, the $\mathrm{pH}$ values of the leaching solution when the oyster shell powder was applied to each treatment were not significantly different from that of the control (CK). However, at the end of the leaching tests, the $\mathrm{pH}$ values of treatments $\mathrm{T} 1, \mathrm{~T} 2, \mathrm{~T} 3$, and $\mathrm{T} 4$ increased by $0.35,1.86,3.65$, and 3.77 , respectively, compared with that of the $\mathrm{CK}$, indicating that adding oyster shell powder can increase the $\mathrm{pH}$ of the soil, and the effect of increasing the $\mathrm{pH}$ value of the soil increased with the amount of oyster shell powder. However, the dynamic changes in the $\mathrm{pH}$ values for $\mathrm{CK}$ and treatment $\mathrm{T} 1$ were almost consistent, indicating that the acidity adjustment effect of oyster shell powder on acidic soil is not ideal when the amount of oyster shell powder is too small. The dynamic changes in $\mathrm{pH}$ values for treatments $\mathrm{T} 3$ and $\mathrm{T} 4$ were also very similar, indicating that an excessively large amount of oyster shell powder will not increase the $\mathrm{pH}$ of the soil. The effect of oyster shell powder treatment on soil $\mathrm{pH}$ may depend on two aspects. First, owing to its alkalinity, the oyster shell powder can neutralize part of the $\mathrm{H}^{+}$ions in the soil to increase the overall $\mathrm{pH}$ value. Additionally, oyster shell powder also contains a large amount of calcium carbonate, which can increase the base saturation and $\mathrm{pH}$ value of the 
soil, while supplementing the calcium in the acidic soil, thereby achieving the purpose of improving the acidity of the soil.

\section{Effect of oyster shell powder on nitrate nitrogen and ammonium nitrogen in leaching solution}

As shown in Fig. 3, the leaching characteristics of $\mathrm{NO}_{3}{ }^{-}$and $\mathrm{NH}_{4}{ }^{+}$in the leaching solution of each treatment were exactly opposite. In the leaching solution treated with oyster shell powder, the concentration and accumulative amount of $\mathrm{NO}_{3}{ }^{-}$were higher than those of $\mathrm{CK}$, whereas the concentration and accumulative amount of $\mathrm{NH}_{4}{ }^{+}$were lower than those of $\mathrm{CK}$, indicating that the application of oyster shell powder to latosol can prevent the leaching loss of $\mathrm{NH}_{4}{ }^{+}$and promote the leaching loss of $\mathrm{NO}_{3}{ }^{-}$in the soil. As shown in Fig. $3 \mathrm{~d}$, the effect of oyster shell powder on preventing leaching loss of $\mathrm{NH}_{4}{ }^{+}$was significant $(\mathrm{P}<0.05)$, and as the amount of oyster shell powder increased, the cumulative amount of $\mathrm{NH}_{4}{ }^{+}$in the leaching solution decreased. Compared with that of the $\mathrm{CK}$, the cumulative leaching amount of $\mathrm{NH}_{4}^{+}$with the oyster shell powder treatments $\mathrm{T} 1$, $\mathrm{T} 2$, T3, and T4 was reduced by $23.90,48.58,56.48$, and $57.25 \%$, respectively. This is because the alkaline oyster shell powder can effectively reduce the $\mathrm{H}^{+}$in the soil and hence, enhance the adsorption capacity of the soil for $\mathrm{NH}_{4}{ }^{+}$. In our study, as the amount of oyster shell powder increased, the adsorption capacity also increased. In addition, the application of oyster shell powder to latosol promoted the leaching loss of $\mathrm{NO}_{3}^{-}(\mathrm{P}<0.05)$, as the cumulative amount of $\mathrm{NO}_{3}{ }^{-}$in the leaching solution treated with oyster shell powder increased by $2.5-5.68$ times (compared to CK). This is because the addition of oyster shell powder increases the $\mathrm{OH}^{-}$content in the soil, causing the $\mathrm{NO}_{3}{ }^{-}$originally adsorbed in the soil to be repelled due to the same charge, leading to desorption and thus, leaching loss. This may also be related to the fact that the addition of oyster shell powder increases the $\mathrm{pH}$ value of the soil, activates nitrous and nitrate bacteria, and promotes the nitrification of a large amount of $\mathrm{NH}_{4}{ }^{+}$. The $\mathrm{NO}_{3}{ }^{-}$thus formed is lost through leaching, ultimately resulting in low utilization of nitrogen fertilizer and groundwater pollution.

\section{Effect of oyster shell powder on total phosphorus in leaching solution}

As shown in Fig. 4a, the phosphorus concentration in the leaching solution of each treatment indicated a slight increase and then, a sharp decline as time passed, as the phosphorus leaching rate reached a maximum between the $11^{\text {th }}$ and $16^{\text {th }}$ day. In addition, the total phosphorus concentration in the leaching solutions treated with oyster shell powder was lower than that of CK. In addition to the total phosphorus concentration in the leaching solution of $\mathrm{T} 2$ treatment peaked on the $1^{\text {th }}$ day, the total phosphorus concentration reached a peak on the $6^{\text {th }}$ day, 
with $\mathrm{CK}$ and the $\mathrm{T} 1, \mathrm{~T} 3$, and $\mathrm{T} 4$ treatments exhibiting peak total phosphorus concentrations of $0.0037,0.0035$, 0.0035 , and $0.0034 \mathrm{mg} / \mathrm{L}$, respectively. This is because phosphorus does not easily migrate in soil; hence, the leaching loss is relatively small. As shown in Fig. 4b, the cumulative amounts of phosphorus in the soil leaching solution across the treatments were different, as the cumulative leaching amount of phosphorus in the treatments $\mathrm{T} 1, \mathrm{~T} 2, \mathrm{~T} 3$, and $\mathrm{T} 4$ was reduced by $6.31 \%, 7.28 \%, 10.07 \%$, and $8.79 \%$, respectively, compared with that of the CK, indicating that the addition of oyster shell powder significantly reduced the cumulative leaching amount of phosphorus in the leaching solution ( $\mathrm{p}<0.05$ ). However, excessive application of oyster shell powder weakened its inhibitory effect on phosphorus leaching in the soil.

\section{Effect of oyster shell powder on total potassium in leaching solution}

The changes in the total potassium concentration in the soil leaching solution for each treatment are shown in Fig. 5a. Throughout the leaching process, the total potassium concentration in the leaching solution treated with oyster shell powder was lower than that of the control, indicating a reduction of $19.22-40.01 \%$. This indicates that oyster shell powder can reduce the leaching loss of potassium and significantly improve fertilizer utilization. The potassium concentration in the leaching solution of all treatments peaked on the $1^{\text {st }}$ day, which decreased significantly as the time and number of leaching tests increased. As shown in Fig. 5b, the four treatments with oyster shell powder (T1, T2, T3, and T4) indicated cumulative leaching amounts of potassium that were reduced by $17.08,17.32,21.65$, and $26.58 \%$, respectively, when compared to CK at the end of the leaching. This is because the addition of oyster shell powder can adjust the $\mathrm{pH}$ value of the soil, reducing the $\mathrm{H}^{+}$ in the soil such that the base ion $\mathrm{K}^{+}$cannot be easily leached. In addition, oyster shell powder is also rich in natural pores, which may enhance the soil's adsorption of potassium and reduce potassium leaching.

\section{Effect of oyster shell powder on leaching loss rate of nutrients}

As shown in Fig. 6, treatment with oyster shell powder indicated an inhibitory effect on the leaching of some nutrients in the soil, and the leaching loss rate followed the order of $\mathrm{NH}_{4}{ }^{+}<\mathrm{K}<\mathrm{P}<\mathrm{NO}_{3}{ }^{-}$. In particular, the loss rate of ammonium nitrogen treated by oyster shell powder was $-82.41--34.40 \%$, loss rate of potassium was $-35.28--$ $22.67 \%$, and loss rate of phosphorus was $-0.04--0.02 \%$. Moreover, as the amount of oyster shell powder in the latosol samples increased, the loss rates of ammonium nitrogen and potassium in the soil decreased. The results indicated that the application of oyster shell powder to soil can significantly reduce the leaching loss of ammonium nitrogen, phosphorus, and potassium in the soil; notably, this is closely related to the leaching 
characteristics of nutrients and the adsorption characteristics of oyster shell powder. However, the loss rate of nitrate nitrogen was as high as $192.86-435.20 \%$, except for CK, indicating that adding oyster shell powder can increase the probability of nitrate nitrogen leaching loss in soil significantly. This is because the soil already contained $\mathrm{NH}_{4}{ }^{+}$from the decomposition of urea. Notably, the application of oyster shell powder may affect the nitrification of the soil, thus, accelerating the conversion process from $\mathrm{NH}_{4}{ }^{+}$to $\mathrm{NO}_{3}{ }^{-}$. In addition, adding oyster shell powder increases the negative charge of clay mineral particles in soil, thereby weakening the adsorption effect of soil for $\mathrm{NO}_{3}{ }^{-}$and promoting the leaching of $\mathrm{NO}_{3}{ }^{-}$in the soil.

\section{Effect of oyster shell powder on leaching amount}

The trend of the leaching solution volume for each treatment is shown in Fig. 7. After the leaching process was completed, there was no significant difference in the total volume of the leaching solution collected in the soil columns that were treated with $\mathrm{T} 1, \mathrm{~T} 2, \mathrm{~T} 3$, and $\mathrm{T} 4$, following the order of $\mathrm{CK}<\mathrm{T} 1<\mathrm{T} 2<\mathrm{T} 4<\mathrm{T} 3$. Compared with CK, the leaching amount of oyster shell powder in samples with treatments $\mathrm{T} 1, \mathrm{~T} 2, \mathrm{~T} 3$, and $\mathrm{T} 4$ were reduced by $1.21,1.62,2.65$, and $2.52 \%$, respectively, indicating that adding oyster shell powder can reduce the leaching loss of soil water content and maintain the field water retention capacity of the soil. In addition, the soil columns with high proportions of oyster shell powder exhibited better water retention effect. This may be because oyster shell powder has a large number of natural pores on its surface, which can increase the water retention capacity of the soil through its own moisture absorption effect. However, the residual water in the soil column may evaporate during the time intervals between the leaching tests, and the evaporation rate will be slightly different, such that the leaching amount increases slightly when the amount of oyster shell powder exceeds $0.4 \%$. Overall, in our study, the water absorption rate of oyster shell powder in latosol was 4.67-18.00\%, which had a certain water retention effect.

\section{Discussions}

\section{Effect of different fertilizer application amounts on leaching characteristics of nutrients in latosol}

Latosol has poor water and fertilizer retention capacity (Bhat and Sujatha 2009; Murmu et al. 2016), and its nutrients are prone to leaching loss. In our study, the leaching amount of phosphorus and potassium in the soil increased with the application amounts of phosphorus and potassium fertilizers, similar to the findings of other studies (Rosolem et al. 2006; Zhao et al. 2009). However, different studies have led to different conclusions regarding whether the application of nitrogen fertilizer promotes or inhibits the leaching loss of potassium in the 
soil. In this study, the leaching loss of nitrogen in the leaching solution increased linearly with the amount of nitrogen fertilizer, which is consistent with the results of Qiao et al. (2013) and Russo et al. (2017). However, Salazar et al. (2012) conducted a the leaching test of volcanic soil and observed that when the application amount of urea was high, the nitrogen leaching loss was very small, which was different from the findings of our study. This may be due to the extremely high content of humus in the volcanic soil, which can fix the elements to a certain degree, thus, preventing the leaching loss of nitrogen in the soil. Nguyen et al. (2020) also confirmed that soil nutrient leaching differs due to different soil properties. In addition, the type of fertilizer is also an important factor that affects the leaching characteristics of soil nutrients (Fang-chun et al. 2010; Ai-ping et al. 2015). Fan and $\mathrm{Li}$ (2009) observed that the net nitrogen leaching loss of ammonium nitrate was greater than that of slow-release nitrogen fertilizer in both loam and sandy soils. Notably, long-term excessive application of acidic fertilizers, such as ammonium nitrate and superphosphate, not only increases the cost but also causes a series of environmental problems, such as soil acidification and water pollution. Moreover, Onwu et al. (2018) and Shi et al. (2017) found that the application of organic fertilizers can improve the retention of soil nutrients, reduce the loss of nutrients in the short term after fertilization, and improve fertilizer utilization. Nevertheless, the long-term application of organic fertilizers may also cause a large amount of nutrient leaching loss, similar to the use of chemical fertilizers (Yan et al. 2017). Notably, the simultaneous application of both chemical fertilizers and organic fertilizers can the improve soil nutrient content (Han et al. 2016; Selvakumar et al. 2018) and effectively reduce soil nutrient leaching (Lentz and Lehrsch 2018) . In the future, it will be necessary to conduct an in-depth comparative study on the soil nutrient leaching characteristics of other fertilizers, after clarifying the application amounts of conventional fertilizers.

\section{Effect of different oyster shell powder application amounts on leaching characteristics of nutrients in latosol}

Our study findings indicated that a larger amount of oyster shell powder can lead to a higher $\mathrm{pH}$ value of the leaching solution, thus, improving the acidity of the soil to a larger extent. This is achieved because the oyster shell powder is slightly soluble in water, which forms free $\mathrm{OH}^{-}$ions that neutralize the $\mathrm{H}^{+}$in the soil and thus, increase the $\mathrm{pH}$ value. In addition, latosol experiences a strong desiliconization and aluminization effect. Lawrence et al. (1995) observed that acid deposition can activate soil aluminization and cause calcium deficiency, and the contents of $\mathrm{Ca}^{2+}$ and $\mathrm{Al}^{3+}$ in the soil are significantly negatively correlated. The $\mathrm{Ca}^{2+}$ in the soil is exchanged by $\mathrm{H}^{+}$and $\mathrm{Al}^{3+}$ to enhance the base saturation of the soil, thus, increasing the $\mathrm{pH}$ of the soil (Mehmood et al. 2017). In addition, because the main component of oyster shell powder is calcium carbonate, it 
can replenish $\mathrm{Ca}^{2+}$ in the soil. Due to its significant ameliorating effect on the acidified and low-calcium latosol, oyster shell powder has the potential to replace lime for acidic soil amendment.

The adsorption of fertilizer elements is an inherent factor that improves the anti-leaching effect of soils (Kang et al. 2011). Oyster shell powder has an inhibitory effect on the leaching of ammonium nitrogen, phosphorus, and potassium in the soil. This is because oyster shell powder can strengthen the adsorption and retention of the fertilizer in the soil due to its own porous structure, reduce the fertilizer entering the liquid phase in the soil, inhibit the loss of nutrients, and improve the utilization rate of the fertilizer. The application of biochar, in terms of soil nutrient leaching, has become a hot research topic (Rubin et al. 2020; Ukwattage et al. 2020; Partovi et al. 2021); there are also a few reports on the practical application of oyster shell powder in this field. Biochar can reduce soil nutrient leaching loss through adsorption and the formation of aggregates in the soil (Xiao and Meng 2020), but the adjustment of acidity is not as obvious as that observed by the application of waste oyster shell powder, nor can it supplement $\mathrm{Ca}^{2+}$ in the soil simultaneously. Thus, oyster shell powder is a potential environmentally friendly biomass soil amendment. However, we observed that oyster shell powder promotes the leaching of nitrate nitrogen, which is positively correlated with the amount of oyster shell powder applied. Therefore, we recommend avoiding mixed application of oyster shell powder and nitrate nitrogen fertilizer as much as possible. Instead, we promote the use of urease inhibitors to reduce the risk of nitrogen fertilizer loss and water eutrophication. Notably, the particle size and calcination of oyster shell powder, along with the application amount, also have a certain impact on soil improvement (Alidous et al. 2015; Yinglan et al. 2016), which should be further studied to clarify the effect of oyster shell powder application, especially in terms of acidity adjustment and retention of water and fertilizer in soil.

\section{Conclusions}

(1) The nutrient leaching losses of urea, superphosphate, and potassium chloride all indicated a linear increase with increasing amount of fertilizer application. In particular, the nitrate nitrogen in urea and potassium in potassium chloride were the most likely to be leached, followed by the phosphorus in superphosphate, whereas ammonium nitrogen in urea was the most difficult to leach.

(2) When the oyster shell powder was applied to the latosol for leaching, the $\mathrm{pH}$ value of the leaching solution increased significantly. The $\mathrm{pH}$ value increased as the amount of oyster shell powder added to the latosol increased, and thus, we were able to deduce that oyster shell powder can improve the soil acidity of latosol. 
(3) In our study, the addition of oyster shell powder improved the retention of water and fertilizer in latosol. It also has a significant inhibitory effect on the loss of ammonium nitrogen, phosphorus, and potassium in soil. The leaching loss of ammonium nitrogen and potassium in the leaching solution decreased as the amount of oyster shell powder applied increased, and the leaching loss of phosphorus was the lowest when $0.4 \%$ oyster shell powder was added.

(4) The leaching characteristics of nitrate nitrogen in the leaching solution treated with oyster shell powder were different from those of other nutrients. In this study, we observed that oyster shell powder greatly increases the loss of nitrate nitrogen, and is thus, not suitable as an inhibitor of nitrate nitrogen in latosol. Nevertheless, the increase or decrease in the amount of oyster shell powder has a profound impact on latosol. Thus, the addition of oyster shell powder can reduce or increase the leaching of certain nutrients. Notably, the short-term effect of oyster shell powder on the leaching of soil nutrients depends largely on the soil type. In addition to the amount of oyster shell powder, ultrafine grinding and calcination methods are also important factors that influence the improvement of acidic soil by oyster shell powder, which we aim to explore in our future work.

Acknowledgements The authors are grateful to several students and the staff of the Institute of Agricultural Biotechnology, Guangdong Ocean University of China, for their help with the fieldwork and lab work involved in this study.

Author Contributions All authors contributed to the study conception and design. Material preparation, data collection, and analysis were performed by HUANG, Yongxiang, LIU, Kexing, and ZHENG, Chao. The first draft of the manuscript was written by YANG, Xiaofei, and all authors commented on previous versions of the manuscript. All authors have read and approved the final manuscript.

Funding This work was supported by a special fund for Agro-Scientific Research in the Public Interest of China (Grant No. 20120301303) and Science and Technology Planning Project of Guangdong Province, China (Grant No. 2016A020210052).

Data availability All data are mentioned in the body of manuscript, tables, and figure. 
419 Declarations

420

421 Ethics approval and consent to participate Not applicable.

422

423 Consent for publication Not applicable.

424

425 Competing interests The authors declare no competing interests. 


\section{References}

Alidoust D, Kawahigashi M, Yoshizawa S et al. (2015) Mechanism of cadmium biosorption from aqueous solutions using calcined oyster shells. J Environ Manage 150:103-110. DOI: 10.1016/j.jenvman.2014.10.032

Ai-ping Z, Ji G, Ru-liang L et al. (2015) The comparison of different fertilizer technologies on nitrogen leaching losses and nitrogen use efficiency in rice production — - Taking Ningxia irrigation region as an example. J Agric Resour Environ 32:175-184. DOI: 10.13254/j.jare.2014.0334

Bhat R, Sujatha S (2009) Soil fertility and nutrient uptake by arecanut (Areca catechu L.) as affected by level and frequency of fertigation in a laterite soil. Agric Water Manag 96:445-456. DOI: 10.1016/j.agwat.2008.09.007

Elbl J, Šimečková J, Škarpa P et al. (2020) Comparison of the agricultural use of products from organic waste processing with conventional mineral fertilizer: Potential effects on mineral nitrogen leaching and soil quality. Agronomy 10:226. DOI: 10.3390/agronomy10020226

Eo J, Kim M, Nam H, Kwon S, Song Y (2018) Effect of Organic Waste Application on Soil Chemical Properties and Organisms under Zelkova serrata Cultivation Korean Journal of Environmental Biology 36:471-478. DOI: 10.11626/KJEB.2018.36.4.471

Fan XH, Li YC (2009) Effects of slow-release fertilizers on tomato growth and nitrogen leaching. Commun Soil Sci Plant Anal 40:3452-3468. DOI: 10.1080/00103620903326016

Guo JH, Liu XJ, Zhang Y et al. (2010) Significant acidification in major Chinese croplands. Science 327:10081010. DOI: 10.1126/science. 1182570

Guo M (2009) Soil sampling and methods of analysis. J Environ Qual 38:375-375. DOI: $10.2134 /$ jeq2008.0018br

Han SH, An JY, Hwang J et al. (2016) The effects of organic manure and chemical fertilizer on the growth and nutrient concentrations of yellow poplar (Liriodendron Tulipifera Lin.) in a nursery system. Forest Sci Technol 12:137-143. DOI: 10.1080/21580103.2015.1135827

Hong M, Jang I, Son Y et al. (2021) Agricultural by-products and oyster shell as alternative nutrient sources for microbial sealing of early age cracks in mortar. AMB Express 11:11. DOI: 10.1186/S13568-02001166-5 
Islam MN, Islam M, Rahman M, Mian M, Ali M (2016) Effect of fertilizer management on NPKS leaching loss from sandy loam soil under alternate wetting and drying condition. Bangladesh Rice J 20:59-64. DOI: 10.3329/brj.v20i1.30630

Jay JG, Tyler-Plog M, Brown SL, Grothkopp F (2019) Nutrient, metal, and organics removal from stormwater using a range of bioretention soil mixtures. J Environ Qual 48:493-501. DOI: $10.2134 /$ jeq2018.07.0283

Jiang Y, Nyiraneza J, Khakbazan M et al. (2019) Nitrate leaching and potato yield under varying plow timing and nitrogen rate. Agrosyst Geosci Environ 2:1-14. DOI: 10.2134/age2019.05.0032

Kang J, Amoozegar A, Hesterberg D et al. (2011) Phosphorus leaching in a sandy soil as affected by organic and inorganic fertilizer sources. Geoderma 161:194-201. DOI: 10.1016/j.geoderma.2010.12.019

Krause HH (1965) Effect of pH on leaching losses of potassium applied to forest nursery soils. Soil Sci Soc Am J 29:613-615. DOI: 10.2136/SSSAJ1965.03615995002900050037X

Lawrence GB, David MB, Shortle WC (1995) A new mechanism for calcium loss in forest-floor soils. Nature 378:162-165. DOI:10.1038/378162a0

Lee M, Tsai WS, Chen ST (2020) Reusing shell waste as a soil conditioner alternative? A comparative study of eggshell and oyster shell using a life cycle assessment approach. J Cleaner Prod 265:121845. DOI: 10.1016/j.jclepro.2020.121845

Lentz RD, Lehrsch GA (2018) Mineral fertilizer and manure effects on leached inorganic nitrogen, nitrate isotopic composition, phosphorus, and dissolved organic carbon under furrow irrigation. J Environ Qual 47:287-296. DOI:10.2134/jeq2017.09.0384

Wang L, Xin J, Nai H, Zheng X (2021) Effects of different fertilizer applications on nitrogen leaching losses and the response in soil microbial community structure. Environ Technol Innov 23. DOI: 10.1016/J.ETI.2021.101608, 101608

Li Y, Cui-ping SUN, Yong-ping J et al. (2017) Effects of long-term application of organic manure on soil fertility and nitrate-N transport in fluvo-aquic soil. J Agro Environ Sci 36:1386-1394

Liu FC, Xing SJ, Duan CH et al. (2010) [Nitrate nitrogen leaching and residue of humic acid fertilizer in field soil].[J]. Huan jing ke xue 31:1619-1624. DOI: 10.1631/jzus.A1000244

Mehmood K, Jy L, Jiang J et al. (2017) Effect of low energy-consuming biochars in combination with nitrate fertilizer on soil acidity amelioration and maize growth. J Soils Sediments 17:790-799. DOI: 
Minikaev D, Surge U, Tripler E, Gelfand I' (2021) Effect of increasing nitrogen fertilization on soil nitrous oxide emissions and nitrate leaching in a young date palm (Phoenix dactylifera L., cv. Medjool) orchard. Agric Ecosyst Environ Orchard[J] 319:1-11. DOI: 10.1016/J.AGEE.2021.107569

Murmu K, Swain D, Ghosh B (2016) Effect of mineral and organic nutrient management on sweet corn production system in acid lateritic soil of India. J Earth Environ Health Sci 2:70-76. DOI: $10.4103 / 2423-7752.191398$

Nguyen BT, Phan BT, Nguyen TX et al. (2020) Contrastive nutrient leaching from two differently textured paddy soils as influenced by biochar addition. J Soils Sediments 20:297-307. DOI: 10.1007/s11368019-02366-8

Onwu AC, Osujieke ND, Gani AT, Ali A (2018) Influence of Organic Fertilizer (Nomau®) on Soil, Leaf Nutrient Content, Growth and Yield of physic Nut (Jatropha curcas) in Makurdi, North Central, Nigeria. AJSSPN 3:1-11. DOI: 10.9734/AJSSPN/2018/42090

Park WH, Park WH, Polprasert C (2008) Phosphorus adsorption characteristics of oyster shells and alum sludge and their application for nutrient control in constructed wetland system. J Environ Sci Health A Tox Hazard Subst Environ Eng 43:511-517. DOI: 10.1080/10934520701796440

Partovi Z, Ramezani Etedali H, Kaviani A and Ramezani Etedali Hadi and Kaviani Abbas (2021) Effects of applying biochar and straw on nitrate leaching and maize yield production. Water Environ J 35:943950. DOI: 10.1111/WEJ.12684

Qiao J, Yang L, Yan T et al. (2013) Rice dry matter and nitrogen accumulation, soil mineral N around root and N leaching, with increasing application rates of fertilizer. Eur J Agron 49:93-103. DOI: 10.1016/j.eja.2013.03.008

Rosolem CA, Arroyo Garcia R, Foloni JSS, Calonego JC (2006) Potassium leaching in soil as affected by potassium fertilizer rates applied over pearl millet straw. Rev Bras Cien Solo 30:813-819

Rubin RL, Anderson TR, Ballantine KA (2020) Biochar simultaneously reduces nutrient leaching and greenhouse gas emissions in restored wetland soils. Wetlands 40:1-5. DOI: 10.1007/s13157-020$01380-8$

Russo TA, Tully K, Palm C, Neill C (2017) Leaching losses from Kenyan maize cropland receiving different rates of nitrogen fertilizer. Nutr Cycl Agroecosyst 108:195-209. DOI: 10.1007/s10705-017-9852-z 
Salazar F, Martínez-Lagos J, Alfaro M, Misselbrook T (2012) Low nitrogen leaching losses following a high rate of dairy slurry and urea application to pasture on a volcanic soil in Southern Chile. Agric Ecosyst Environ 160:23-28. DOI: 10.1016/j.agee.2012.04.018

Selvakumar G, Yi PH, Lee SE, Han SG (2018) Short-term fertilization with hairy vetch, compost and chemical fertilizer affect red pepper yield and quality and soil properties. Korean J Environ Agric 37:9-14. DOI: 10.5338/KJEA.2018.37.1.10

Sharpley AN, Smith SJ, Stewart BA, Mathers AC (1984) Forms of phosphorus in soil receiving cattle feedlot Waste1. J Environ Qual 13:211-215. DOI:10.2134/jeq1984.00472425001300020007x

Shi W-X, Shi-Liang Liu YZ et al. (2017) Effects of pig manure organic fertilizer application on available nutrient content and soil aggregate distribution in Fluvo-aquic soil. J Agric Resour Environ 34:431438. DOI: $10.13254 /$ j.jare.2017.0070

Tunney H, Carton OT, Brookes PC, et al. (1997) Phosphorus loss from soil to water CA B International, pp 253-271

Ukwattage NL, Li Y, Gan Y et al. (2020) Effect of biochar and coal fly ash soil amendments on the leaching loss of phosphorus in subtropical sandy ultisols. Water Air Soil Pollut 231:1-18. DOI: $10.1007 /$ s11270-020-4393-5

Xiao L, Meng F (2020) Evaluating the effect of biochar on salt leaching and nutrient retention of Yellow River Delta soil. Soil Use Manag 36:740-750. DOI: 10.1111/SUM.12638

Yinglan C, Lina C, Jinli Z, Zhiyong H (2016) Effects of oyster shell powder on the remediation and stabilization of acid Cd pollution soil. Environ Sci Technol 39:178-182

Zhao M, Chen X, Shi Y et al. (2009) Phosphorus vertical migration in aquic Brown soil and light chernozem under different phosphorous application rate: A soil column leaching experiment. Bull Environ Contam Toxicol 82:85-89. DOI: 10.1007/s00128-008-9586-3 
Tables

Table 1 Basic physicochemical properties of the tested materials

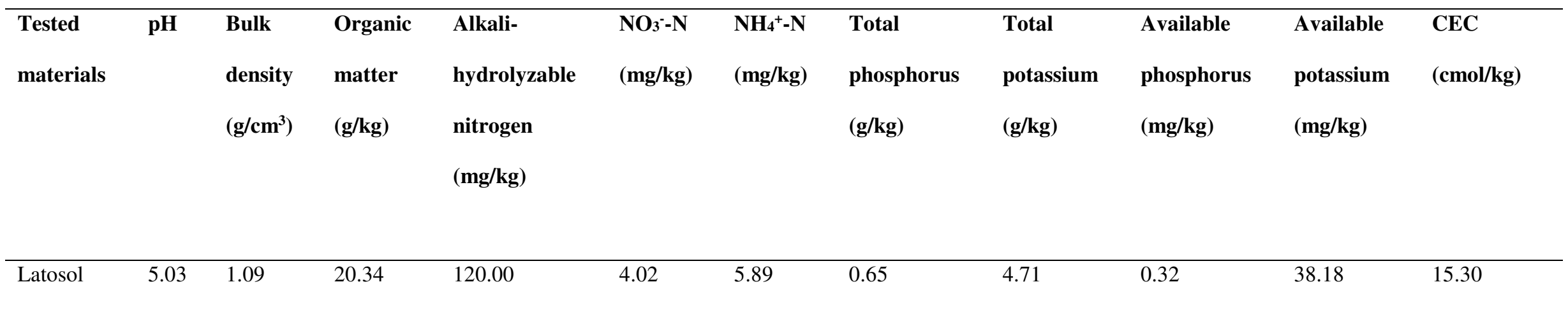

537 *Note: Cation exchange capacity (CEC) 
Table 2 Actual application amount of test materials (g/column)

\begin{tabular}{|c|c|c|c|c|c|c|c|}
\hline \multirow{2}{*}{$\begin{array}{l}\text { Application } \\
\text { level }\end{array}$} & \multicolumn{3}{|c|}{$\begin{array}{l}\mathbf{1}^{\text {st }} \text { cultivation test (including } 3 \\
\text { independent leaching tests) }\end{array}$} & \multicolumn{4}{|c|}{$2^{\text {nd }}$ cultivation test } \\
\hline & $\mathbf{N} / \mathbf{U}$ & $\mathbf{P}$ & $\mathbf{K}$ & Urea & Superphosphate & $\begin{array}{l}\text { Potassium } \\
\text { chloride }\end{array}$ & $\begin{array}{l}\text { Oyster } \\
\text { shell } \\
\text { powder }\end{array}$ \\
\hline 1 & 0 & 0 & 0 & 0.4348 & 0.6250 & 0.3846 & 0 \\
\hline 2 & 0.1087 & 0.1563 & 0.0962 & 0.4348 & 0.6250 & 0.3846 & 0.5000 \\
\hline 3 & 0.2174 & 0.3125 & 0.1923 & 0.4348 & 0.6250 & 0.3846 & 1.0000 \\
\hline 4 & 0.4348 & 0.6250 & 0.3846 & 0.4348 & 0.6250 & 0.3846 & 2.0000 \\
\hline 5 & 0.8696 & 1.2500 & 0.7692 & 0.4348 & 0.6250 & 0.3846 & 4.0000 \\
\hline
\end{tabular}

539 *Note: The first cultivation test included three independent leaching tests that were conducted simultaneously.

$540 \mathrm{~N} / \mathrm{U}$ represents the actual amount of urea used to determine the five application levels of nitrate nitrogen and

541 ammonium nitrogen in the first leaching test; P represents the actual amount of superphosphate used to

542 determine the five application levels of total phosphorus in the second leaching test, and $\mathrm{K}$ represents the actual

543 amount of potassium chloride used to determine the five application levels of total potassium in the third

544 leaching test. In the second cultivation test, we simultaneously added $0.4348 \mathrm{~g}$ urea, $0.6250 \mathrm{~g}$ superphosphate,

545 and $0.3846 \mathrm{~g}$ potassium chloride to $500 \mathrm{~g}$ of latosol. Notably, different amounts of oyster shell powder were

546 added to each leaching test. 
Table 3 Nitrate leaching characteristics of urea in latosol

\begin{tabular}{|c|c|c|c|c|c|c|c|}
\hline \multirow[t]{2}{*}{ Treatment } & \multicolumn{5}{|c|}{ Dynamic concentration change $(\mathrm{mg} / \mathrm{L})$} & \multirow{2}{*}{$\begin{array}{l}\text { Cumulative } \\
\text { amount } \\
\text { (mg) }\end{array}$} & \multirow{2}{*}{$\begin{array}{l}\text { Loss rate } \\
(\%)\end{array}$} \\
\hline & $1 \mathrm{~d}$ & $8 \mathrm{~d}$ & $15 \mathrm{~d}$ & $22 \mathrm{~d}$ & $29 d$ & & \\
\hline N0 & $2.86 \pm 0.53^{\mathrm{a}}$ & $5.62 \pm 0.14^{\mathrm{c}}$ & $5.67 \pm 0.12^{\mathrm{b}}$ & $6.08 \pm 0.12^{\mathrm{b}}$ & $6.05 \pm 0.02^{\mathrm{b}}$ & $4.09 \pm 0.01^{\mathrm{d}}$ & $0.00 \pm 0.00^{\mathrm{b}}$ \\
\hline $\mathrm{N} 1$ & $2.88 \pm 0.24^{\mathrm{a}}$ & $5.71 \pm 0.04^{\mathrm{c}}$ & $5.73 \pm 0.37^{\mathrm{ab}}$ & $6.15 \pm 0.02^{\mathrm{b}}$ & $6.07 \pm 0.04^{\mathrm{ab}}$ & $4.15 \pm 0.00^{c}$ & $63.10 \pm 4.21^{\mathrm{a}}$ \\
\hline $\mathrm{N} 2$ & $3.31 \pm 1.58^{\mathrm{a}}$ & $5.83 \pm 0.04^{\mathrm{b}}$ & $5.90 \pm 0.16^{\mathrm{ab}}$ & $6.30 \pm 0.18^{\mathrm{ab}}$ & $6.07 \pm 0.08^{\mathrm{ab}}$ & $4.26 \pm 0.06^{\mathrm{b}}$ & $77.87 \pm 27.45^{\mathrm{a}}$ \\
\hline N3 & $3.40 \pm 1.16^{\mathrm{a}}$ & $5.86 \pm 0.07^{\mathrm{ab}}$ & $5.92 \pm 0.36^{\mathrm{ab}}$ & $6.32 \pm 0.12^{\mathrm{a}}$ & $6.09 \pm 0.09^{\mathrm{ab}}$ & $4.36 \pm 0.17^{\mathrm{ab}}$ & $55.55 \pm 38.31^{\mathrm{a}}$ \\
\hline N4 & $3.54 \pm 0.62^{\mathrm{a}}$ & $5.95 \pm 0.04^{\mathrm{a}}$ & $6.01 \pm 0.02^{\mathrm{a}}$ & $6.41 \pm 0.07^{\mathrm{a}}$ & $6.10 \pm 0.02^{\mathrm{a}}$ & $4.46 \pm 0.09^{\mathrm{a}}$ & $42.53 \pm 10.76^{\mathrm{a}}$ \\
\hline U0 & $0.61 \pm 0.10^{\mathrm{a}}$ & $0.44 \pm 0.03^{c}$ & $0.35 \pm 0.07^{\mathrm{c}}$ & $0.25 \pm 0.21^{\mathrm{d}}$ & $0.22 \pm 0.05^{\mathrm{d}}$ & $0.29 \pm 0.05^{\mathrm{d}}$ & $0.00 \pm 0.00^{\mathrm{d}}$ \\
\hline $\mathrm{U} 1$ & $0.60 \pm 0.14^{\mathrm{a}}$ & $061 \pm 0.15^{\mathrm{bc}}$ & $0.67 \pm 0.20^{\mathrm{b}}$ & $0.71 \pm 0.19^{\mathrm{c}}$ & $0.77 \pm 0.10^{c}$ & $0.53 \pm 0.06^{\mathrm{c}}$ & $220.20 \pm 53.67^{\mathrm{a}}$ \\
\hline $\mathrm{U} 2$ & $0.68 \pm 0.24^{\mathrm{a}}$ & $0.75 \pm 0.06^{\mathrm{b}}$ & $0.76 \pm 0.07^{\mathrm{b}}$ & $0.76 \pm 0.07^{\mathrm{c}}$ & $0.81 \pm 0.11^{\mathrm{c}}$ & $0.60 \pm 0.09^{\mathrm{bc}}$ & $141.33 \pm 40.11^{\mathrm{ab}}$ \\
\hline U3 & $0.67 \pm 0.20^{\mathrm{a}}$ & $0.92 \pm 0.20^{\mathrm{ab}}$ & $0.91 \pm 0.14^{\mathrm{ab}}$ & $0.97 \pm 0.05^{b}$ & $1.05 \pm 0.07^{\mathrm{b}}$ & $0.71 \pm 0.06^{\mathrm{b}}$ & $97.37 \pm 13.83^{b}$ \\
\hline U4 & $0.61 \pm 0.15^{\mathrm{a}}$ & $0.96 \pm 0.04^{\mathrm{a}}$ & $1.03 \pm 0.04^{\mathrm{a}}$ & $1.11 \pm 0.02^{\mathrm{a}}$ & $1.77 \pm 0.22^{\mathrm{a}}$ & $0.87 \pm 0.01^{\mathrm{a}}$ & $67.23 \pm 1.18^{\mathrm{c}}$ \\
\hline
\end{tabular}

548 *Note: Urea was used as a source of nitrogen. $\mathrm{N}$ represents treatment with nitrate nitrogen, and U represents 549 treatment with ammonium nitrogen. The associated numbers from 0 to 4 represent the application levels of pure

$550 \mathrm{~N}$ in urea at $0,100,200,400$, and $800 \mathrm{mg} / \mathrm{kg}$, respectively. In addition, the pure $\mathrm{N}$ application level of urea was

551 linearly related to the cumulative leaching amount of nitrate nitrogen, expressed as $y=0.0009 x+4.1287$

$552 \quad\left(\mathrm{R}^{2}=0.9163\right)$; the pure $\mathrm{N}$ application level of urea was linearly related to the cumulative leaching amount of 553 ammonium nitrogen, expressed as $\mathrm{y}=0.0006 \mathrm{x}+0.4087\left(\mathrm{R}^{2}=08653\right)$. Same superscript letters indicate that there 554 was no significant difference between the inner values of the column at the level of $\mathrm{P}<0.05$ based on Tukey's 555 studentized range test. 
Table 4 Phosphorus leaching characteristics of calcium superphosphate in latosol

\begin{tabular}{|c|c|c|c|c|c|c|c|}
\hline \multirow[t]{2}{*}{ Treatment } & \multicolumn{5}{|c|}{ Dynamic concentration change (mg/L) } & \multirow{2}{*}{$\begin{array}{l}\text { Cumulative } \\
\text { amount } \\
\text { (mg) }\end{array}$} & \multirow{2}{*}{$\begin{array}{l}\text { Loss rate } \\
(\%)\end{array}$} \\
\hline & $1 \mathrm{~d}$ & $8 \mathrm{~d}$ & $15 \mathrm{~d}$ & $22 \mathrm{~d}$ & $29 \mathrm{~d}$ & & \\
\hline P0 & $0.10 \pm 0.00^{\mathrm{e}}$ & $0.11 \pm 0.01^{\mathrm{e}}$ & $0.13 \pm 0.05^{\mathrm{e}}$ & $0.13 \pm 0.03^{\mathrm{e}}$ & $0.13 \pm 0.04^{\mathrm{d}}$ & $0.10 \pm 0.00^{\mathrm{e}}$ & $0.00 \pm 0.00^{\mathrm{d}}$ \\
\hline $\mathrm{P} 1$ & $0.18 \pm 0.01^{\mathrm{d}}$ & $0.30 \pm 0.01^{\mathrm{d}}$ & $0.25 \pm 0.03^{\mathrm{d}}$ & $0.20 \pm 0.01^{\mathrm{d}}$ & $0.17 \pm 0.03^{\mathrm{d}}$ & $0.18 \pm 0.00^{\mathrm{d}}$ & $51.29 \pm 3.14^{\mathrm{c}}$ \\
\hline $\mathrm{P} 2$ & $1.01 \pm 0.01^{\mathrm{c}}$ & $0.47 \pm 0.01^{\mathrm{c}}$ & $0.35 \pm 0.02^{\mathrm{c}}$ & $0.27 \pm 0.02^{\mathrm{c}}$ & $0.36 \pm 0.02^{\mathrm{c}}$ & $0.40 \pm 0.02^{\mathrm{c}}$ & $96.40 \pm 6.30^{\mathrm{a}}$ \\
\hline P3 & $2.44 \pm 0.01^{\mathrm{b}}$ & $0.58 \pm 0.02^{\mathrm{b}}$ & $0.46 \pm 0.02^{\mathrm{b}}$ & $0.46 \pm 0.00^{\mathrm{b}}$ & $0.46 \pm 0.01^{\mathrm{b}}$ & $0.73 \pm 0.02^{\mathrm{b}}$ & $100.55 \pm 2.93^{\mathrm{a}}$ \\
\hline $\mathrm{P} 4$ & $2.71 \pm 0.01^{\mathrm{a}}$ & $0.64 \pm 0.01^{\mathrm{a}}$ & $0.53 \pm 0.03^{\mathrm{a}}$ & $0.53 \pm 0.02^{\mathrm{a}}$ & $0.54 \pm 0.01^{\mathrm{a}}$ & $0.82 \pm 0.00^{\mathrm{a}}$ & $57.64 \pm 0.30^{\mathrm{b}}$ \\
\hline K0 & $10.63 \pm 1.30^{\mathrm{d}}$ & $13.73 \pm 4.63^{\mathrm{e}}$ & $7.62 \pm 0.97^{\mathrm{e}}$ & $13.37 \pm 1.61^{\mathrm{e}}$ & $12.16 \pm 2.01^{\mathrm{e}}$ & $8.80 \pm 0.64^{\mathrm{e}}$ & $0.00 \pm 0.00^{\mathrm{c}}$ \\
\hline $\mathrm{K} 1$ & $35.63 \pm 6.51^{\mathrm{c}}$ & $24.44 \pm 2.57^{\mathrm{d}}$ & $17.56 \pm 2.78^{\mathrm{d}}$ & $24.71 \pm 4.34^{\mathrm{d}}$ & $23.49 \pm 2.89^{\mathrm{d}}$ & $19.45 \pm 2.63^{\mathrm{d}}$ & $110.64 \pm 27.37^{\mathrm{ab}}$ \\
\hline $\mathrm{K} 2$ & $41.66 \pm 8.30^{c}$ & $42.83 \pm 2.27^{\mathrm{c}}$ & $29.20 \pm 3.49^{c}$ & $32.26 \pm 0.83^{c}$ & $29.97 \pm 2.72^{c}$ & $26.95 \pm 0.65^{\mathrm{c}}$ & $94.36 \pm 3.40^{\mathrm{b}}$ \\
\hline $\mathrm{K} 3$ & $126.07 \pm 32.96^{\mathrm{b}}$ & $75.52 \pm 3.00^{\mathrm{b}}$ & $47.87 \pm 2.55^{\mathrm{b}}$ & $52.18 \pm 5.50^{\mathrm{b}}$ & $49.71 \pm 7.84^{\mathrm{b}}$ & $53.93 \pm 5.09^{b}$ & $117.33 \pm 13.24^{\mathrm{a}}$ \\
\hline K4 & $210.21 \pm 20.05^{\mathrm{a}}$ & $148.02 \pm 4.51^{\mathrm{a}}$ & $100.66 \pm 1.95^{\mathrm{a}}$ & $78.49 \pm 2.61^{\mathrm{a}}$ & $67.56 \pm 3.53^{\mathrm{a}}$ & $90.77 \pm 1.53^{\mathrm{a}}$ & $106.56 \pm 1.99^{\mathrm{a}}$ \\
\hline
\end{tabular}

$400 \mathrm{mg} / \mathrm{kg}$, respectively. $\mathrm{U}$ represents treatment with potassium chloride; the subscripts 0 to 4 represent the application levels of pure $\mathrm{K}_{2} \mathrm{O}$ in potassium chloride at 0 , 100 , 200,400 , and $800 \mathrm{mg} / \mathrm{kg}$, respectively. In addition, the pure $\mathrm{P}_{2} \mathrm{O}_{5}$ application level in superphosphate has a linear relationship with the cumulative leaching amount of 


\section{Figure Captions}

Fig. 1 Structure of the leaching device developed in our study

Fig. 2 Dynamic changes of $\mathrm{pH}$ in leaching solution

CK, untreated oyster shell powder, T1 represents treatment of $0.1 \%$ oyster shell powder, T2 represents treatment with $0.2 \%$ oyster shell powder, T3 represents treatment with $0.4 \%$ oyster shell powder, and T4 represents treatment with $0.8 \%$ oyster shell powder

Fig. 3 Leaching characteristics of (a, b) nitrate nitrogen and (c, d) ammonium nitrogen in leaching solution: (a) portrays dynamic changes in nitrate nitrogen concentration in leaching solution; (b) portrays cumulative amount of nitrate nitrogen leached from leaching solution; (c) portrays dynamic changes in ammonium nitrogen in leaching solution; and (d) portrays cumulative amount of ammonium nitrogen leached from leaching solution In each figure, $\mathrm{CK}$ represents the untreated oyster shell powder, T1 represents treatment with $0.1 \%$ oyster shell powder, T2 represents treatment with $0.2 \%$ oyster shell powder, $\mathrm{T} 3$ represents treatment with $0.4 \%$ oyster shell powder, and T4 represents treatment with $0.8 \%$ oyster shell powder. Same superscript letters indicate that there was no significant difference between the inner values of the column at the level of $\mathrm{P}<0.05$ based on Tukey's studentized range test.

Fig. 4 Leaching characteristics of total phosphorus in leaching solution: (a) portrays dynamic changes in total phosphorus concentration in leaching solution and (b) portrays cumulative leaching amount of total phosphorus in leaching solution

In each figure, CK represents the untreated oyster shell powder, T1 represents treatment with $0.1 \%$ oyster shell powder, T2 represents treatment with $0.2 \%$ oyster shell powder, T3 represents treatment with $0.4 \%$ oyster shell powder, and T4 represents treatment with $0.8 \%$ oyster shell powder. Same superscript letters indicate that there was no significant difference between the inner values of the column at the level of $\mathrm{P}<0.05$ based on Tukey's studentized range test.

Fig. 5 Leaching characteristics of total potassium in leaching solution: (a) portrays dynamic changes in total potassium concentration in leaching solution and (b) portrays cumulative leaching amount of total potassium in leaching solution 
593 In each figure, CK represents the untreated oyster shell powder, T1 represents treatment with $0.1 \%$ oyster shell 594 powder, T2 represents treatment with $0.2 \%$ oyster shell powder, T3 represents treatment with $0.4 \%$ oyster shell 595 powder, and T4 represents treatment with $0.8 \%$ oyster shell powder. Same superscript letters indicate that there 596 was no significant difference between the inner values of the column at the level of $\mathrm{P}<0.05$ based on Tukey's 597 studentized range test.

598

599 Fig. 6 Leaching loss rate of nutrients; CK, untreated oyster shell powder; T1, $0.1 \%$ oyster shell powder; T2, 0.2 $600 \%$ oyster shell powder; T3, $0.4 \%$ oyster shell powder; and T4, $0.8 \%$ oyster shell powder 601

602 Fig. 7 Leaching characteristics of leaching amount: (a) total amount of leaching solution and (b) water retention 603 rate

604 In each figure, CK represents the untreated oyster shell powder, T1 represents treatment with $0.1 \%$ oyster shell 605 powder, T2 represents treatment with $0.2 \%$ oyster shell powder, T3 represents treatment with $0.4 \%$ oyster shell 606 powder, and T4 represents treatment with $0.8 \%$ oyster shell powder. Same superscript letters indicate that there 607 was no significant difference between the inner values of the column at the level of $\mathrm{P}<0.05$ based on Tukey's 608 studentized range test. 


\section{Figures}

\section{Figure 1}

Structure of the leaching device developed in our study

\section{Figure 2}

Dynamic changes of $\mathrm{pH}$ in leaching solution

CK, untreated oyster shell powder, T1 represents treatment of $0.1 \%$ oyster shell powder, T2 represents treatment with $0.2 \%$ oyster shell powder, T3 represents treatment with $0.4 \%$ oyster shell powder, and T4 represents treatment with $0.8 \%$ oyster shell powder

\section{Figure 3}

Leaching characteristics of $(a, b)$ nitrate nitrogen and $(c, d)$ ammonium nitrogen in leaching solution: (a) portrays dynamic changes in nitrate nitrogen concentration in leaching solution; (b) portrays cumulative amount of nitrate nitrogen leached from leaching solution; (c) portrays dynamic changes in ammonium nitrogen in leaching solution; and (d) portrays cumulative amount of ammonium nitrogen leached from leaching solution

In each figure, CK represents the untreated oyster shell powder, T1 represents treatment with $0.1 \%$ oyster shell powder, T2 represents treatment with $0.2 \%$ oyster shell powder, T3 represents treatment with $0.4 \%$ oyster shell powder, and T4 represents treatment with $0.8 \%$ oyster shell powder. Same superscript letters indicate that there was no significant difference between the inner values of the column at the level of $\mathrm{P}<$ 0.05 based on Tukey's studentized range test.

\section{Figure 4}

Leaching characteristics of total phosphorus in leaching solution: (a) portrays dynamic changes in total phosphorus concentration in leaching solution and (b) portrays cumulative leaching amount of total phosphorus in leaching solution

In each figure, CK represents the untreated oyster shell powder, T1 represents treatment with $0.1 \%$ oyster shell powder, T2 represents treatment with $0.2 \%$ oyster shell powder, T3 represents treatment with $0.4 \%$ 
oyster shell powder, and T4 represents treatment with $0.8 \%$ oyster shell powder. Same superscript letters indicate that there was no significant difference between the inner values of the column at the level of $\mathrm{P}<$ 0.05 based on Tukey's studentized range test.

\section{Figure 5}

Leaching characteristics of total potassium in leaching solution: (a) portrays dynamic changes in total potassium concentration in leaching solution and (b) portrays cumulative leaching amount of total potassium in leaching solution

In each figure, CK represents the untreated oyster shell powder, T1 represents treatment with $0.1 \%$ oyster shell powder, T2 represents treatment with $0.2 \%$ oyster shell powder, T3 represents treatment with $0.4 \%$ oyster shell powder, and T4 represents treatment with $0.8 \%$ oyster shell powder. Same superscript letters indicate that there was no significant difference between the inner values of the column at the level of $\mathrm{P}<$ 0.05 based on Tukey's studentized range test.

\section{Figure 6}

Leaching loss rate of nutrients; CK, untreated oyster shell powder; T1, $0.1 \%$ oyster shell powder; $\mathrm{T} 2,0.2 \%$ oyster shell powder; T3, $0.4 \%$ oyster shell powder; and T4, $0.8 \%$ oyster shell powder

\section{Figure 7}

Leaching characteristics of leaching amount: (a) total amount of leaching solution and (b) water retention rate

In each figure, CK represents the untreated oyster shell powder, T1 represents treatment with $0.1 \%$ oyster shell powder, T2 represents treatment with $0.2 \%$ oyster shell powder, T3 represents treatment with $0.4 \%$ oyster shell powder, and T4 represents treatment with $0.8 \%$ oyster shell powder. Same superscript letters indicate that there was no significant difference between the inner values of the column at the level of $P<$ 0.05 based on Tukey's studentized range test. 